\title{
Influence of depression and early adverse experiences on illicit drug dependence: a case-control study
}

\begin{abstract}
Objective: The purpose of this study was to investigate the association between depression and illicit drug dependence among a LatinAmerican population. Method: illicit drug dependent patients $(n=137)$ and controls $(n=274)$ were interviewed using the Diagnostic Interview for Genetic Studies, in order to detect lifetime and current depressive disorder and illicit (cocaine, cannabis or inhalants) substance dependence. A regression analysis was used to estimate the odds ratio for drug dependence according to the diagnosis of depression. Results: The lifetime diagnosis of depression ( $p=0.001 ; O R=4.9 ; 95 \% \mathrm{Cl}, 1.9-12.7)$ predicts illegal drugs dependence. Sociodemographic variables such as male gender ( $p<0.001 ; 0 R=36.8 ; 95 \% \mathrm{Cl}, 11.8-114)$ and occupational situation ( $p=0.002$; $O R=5.0 ; 95 \% \mathrm{Cl}, 1.8-13)$ as well as alcohol dependence $(p=0.01 ; O R=3.4 ; 95 \% \mathrm{Cl}, 1.3-8.7)$ significantly influenced depression and drug dependence. Additional influent factors detected were having parents ( $p=0.006$; OR $=18.9 ; 95 \% \mathrm{Cl}, 2.3-158$ ) or friends $(p<0.001 ; O R=64.4 ; 95 \% \mathrm{Cl}, 6.5-636)$ who are illicit drugs dependents. Conclusion: although a causal relationship between dependence on illicit drugs and depression cannot be determined, comparison of the sequence of events point to the occurrence of depression later in life than dependence. It remains to be determined whether depression is a comorbidity of dependence, sharing etiological factors, or a consequence of drug abuse and/or abstinence.
\end{abstract}

Descriptors: Dependence; Illicit drugs; Depression; Risk factors; Case-control studies

\section{Resumo}

Objetivo: O objetivo do presente estudo foi investigar a associação entre depressão e dependência de drogas ilícitas entre a população Latino-Americana. Método: Indivíduos dependentes de drogas ilícitas $(n=137)$ e controles $(n=274)$ foram entrevistados pela Entrevista Diagnóstica para Estudos Genéticos para investigar desordem depressiva corrente, ou durante sua vida, e dependência de drogas ilícitas (cocaína, maconha ou inalantes). Análise de regressão logística foi usada para estimar a razão de chances para dependência de drogas levando em conta o diagnóstico de depressão. Resultados: 0 diagnóstico de depressão durante sua vida ( $p=0,001$; $O R=4,9 ; 95 \% \mathrm{Cl}, 1,9-12,7)$ prediz a dependência de drogas ilícitas. Os dados sociodemográficos sexo masculino ( $p<0,001 ;$ $O R=36,8 ; 95 \% \mathrm{Cl}, 11,8-114)$ e situação ocupacional ( $p=0,002 ; O R=5,0 ; 95 \% \mathrm{Cl}, 1,8-13)$, e a dependência de álcool $(p=0,01 ; O R=3,4 ; 95 \% \mathrm{Cl}, 1,3-8,7)$ influenciam significativamente a depressão e a dependência de drogas. Ainda, outros fatores importantes que influenciam são ter pais ( $p=0,006 ; O R=18,9 ; 95 \% \mathrm{Cl}, 2,3-158)$ ou amigos $(p<0,001 ; 0 R=64,4 ; 95 \% \mathrm{Cl}$, 6,5-636) dependentes de drogas ilícitas. Conclusão: O delineamento utilizado não possibilitou evidenciar a seqüência de eventos no processo de causalidade. No entanto, a variável depressão ocorreu com maior freqüência após a iniciação do uso de drogas. Sugere-se a realização de estudos para avaliar se a depressão é uma comorbidade da dependência ou uma conseqüência do abuso de drogas ou abstinência.

Descritores: Dependência; Drogas ilícitas; Depressão; Fatores de risco; Estudos de casos e controles

\footnotetext{
1 Information Service on Psychoactive Substances, Division of Pharmacology and Toxicology, Universidade Federal de Ciências da Saúde de Porto Alegre (UFCSPA), Porto Alegre (RS), Brazil

2 Medicine Graduate Program: Medical Sciences, Universidade Federal do Rio Grande do Sul (UFRGS), Porto Alegre (RS), Brazil

3 Department of Preventive Medicine, Universidade Federal de Ciências da Saúde de Porto Alegre (UFCSPA), Porto Alegre (RS), Brazil
}

Correspondence

Maristela Ferigolo

Serviço de Informações sobre Substâncias Psicoativas.

Universidade Federal de Ciências da Saúde de Porto Alegre - UFCSPA

Rua Sarmento Leite, 245 - $3^{\text {rd }}$ floor

90050-170 Porto Alegre, RS, Brazil

Phone/fax: (+55 51) 3303-8764

Email:mari@ufcspa.edu.br 


\section{Introduction}

The lifetime prevalence of illicit drug abuse in individuals with mood disorders is estimated to be $19.4 \%$, and the presence of drug abuse increases the risk for depression by a factor of almost five. ${ }^{1}$ Therefore the comorbidity of drug abuse with depression is well established and may have important therapeutic and prognostic implications. ${ }^{2,3}$ Although the research on environmental, genetic and neurobiological factors of both depression and substance use problems have been conducted independently there is yet a gap in the understanding of the developmental process of depression and substance use problems as co-occurring disorders. ${ }^{3}$ The lack of unidirectional and consistent patterns of association for depression and substance use disorders indicates that multiple mechanisms of comorbidity are likely to be simultaneously active. ${ }^{4}$ Epidemiological surveys reveal that depression is more strongly associated with substance dependence than substance abuse. However, there is currently insufficient data to fully test specific models of comorbidity with respect to drug dependence. This is partly due to the numerous subtypes of drugs. ${ }^{4}$

When studying the temporal ordering of depression (symptoms or disorder) with substance use, there are generally two major hypotheses about which one is antecedent. ${ }^{5-7}$ First is the selfmedication hypothesis: substance abuse problems develop as a mechanism to cope with depression. ${ }^{6}$ The alternative hypothesis is that substance abuse is antecedent and generates neurobiological changes which increase the risk of depression. ${ }^{8,9}$ Studies that tested these hypotheses have found less support for the self-medication (depression first) hypothesis than the hypothesis of substance problems being the first problem. ${ }^{6,10,11}$ Brook et al. have also found that alcohol, marijuana, and other illegal drug use in adolescence and young adulthood significantly predicted later major depressive disorder, even after statistically controlling for age, gender, parental education, family income, and episodes of previous psychiatric symptoms. ${ }^{12}$ One may wonder if there is a more specific role of drug dependence than the more general substance abuse diagnosis on the development of depression. The independence between some of these risk and protective factors has yet to be fully explored. For instance, some conditions may be actual risk factors and others may be only proxies of such risk factors.

In this report we present the results of a case-control study designed to identify depression and several potential risk factors for drug dependence. We aimed at the identification of patients' characteristics more closely related to drug dependence. The research also investigated additional secondary information to assign temporal ordering based on presumed time of onset of depression among drug dependent subjects.

\section{Method \\ 1. Subjects}

A case-control study was accomplished from March 2001 to February 2002, in Porto Alegre, Brazil. The participants were recruited in the outpatient clinics of two general hospitals in Porto Alegre. All individuals were 16 to 40 years old, and were initially screened for exclusion criteria by psychologists and nurses from the hospitals. In this phase, it was evaluated if the individuals had enough physical and emotional health to be interviewed and to verify the necessity of emergency measures that could exclude participation, such as, for example, in cases of acute intoxication, myocardial infarction, or accidents.

All subjects in the case group were dependent on illicit drugs and control subjects were patients seeking medical care for clinical problems, who were not dependent on illicit drugs. We adopted a 2:1 ratio of control subjects to cases. The sample size (315 individuals) was determined based on the frequency of depression, a presumed risk factor for drug dependence. The sample number was increased by $30 \%$ to compensate for possible noncompliance and refusal by patients.

Consecutive convenience sampling was used for cases among patients who were seeking treatment for drug-related problems. Controls were selected by systematic sampling, through randomization of one patient out of five outpatients in evaluation/ treatment for any clinical condition. All participants signed a written informed consent before the assessments, and the study was approved by the Institutional Ethical Review Board ( $n^{\circ}$ 03/2001).

Subjects included as drug abuse cases met the criteria of the Diagnostic Interview for Genetic Studies (DIGS) for dependence on cannabis, cocaine and/or inhalants. ${ }^{13}$ Individuals undergoing a psychotic fit, severely intoxicated at the time of the interview or unable to speak or to provide information were excluded. The other exclusion condition for cases was having already been under drug dependence treatment. Around $20 \%$ of the drug dependent individuals referred to the study through the initial screening did not meet final inclusion criteria or did not consent to participate in the study.

Urine samples were collected under supervision, immediately after the interview from both cases and controls. The samples were refrigerated and referred to the Laboratory of Emergency Analysis of the Toxicological Information Center of Porto Alegre. Abuse drugs and their metabolites were detected by a qualitative enzymatic immunoassay. Individuals assigned to the control group should not meet the criteria for illicit drug dependence and should test negative in the urinary toxicological screening. Of the initial group assigned as control patients, $3 \%$ screened positively for illicit drugs in the toxicological tests and were excluded.

\section{Procedure and assessments}

Measurement of potential risk factors was performed with a protocol discriminating age and other socio-demographic characteristics. Additional tools used in this study were: 1) the DIGS ${ }^{14}$ for mood and drug dependence discrimination; 2) the Alcohol Use Disorders Identification Test (AUDIT);15 3) the WHO-Research and Reporting on the Epidemiology of Drug Dependence Questionnaire, adapted for drug screening in Brazil; ${ }^{16}$ and 4) the Conflict Tactics Scales (CTS) for young age adverse experiences. ${ }^{17}$

Dependence on cannabis, cocaine and/or inhalants, and depressive disorder were assessed using the Portuguese version of the DIGS. ${ }^{13}$ The DIGS, a semi-structured clinical interview offers a comprehensive assessment of the consumption, abuse and dependence of drugs, and assessment of major mood and psychotic disorders and their spectrum conditions. DIGS is a polydiagnostic interview covering the Feighner, RDC (Research Diagnostic Criteria), modified RDC, DSM-III (American Psychiatric Association), DSM-III-R, and ICD-10 (World Health Organization) diagnostic systems, and DSM-IV proposed guidelines for somatization and schizophrenia. ${ }^{14}$ The DIGS database is designed to gather all the known clinical data on a subject, including a complete history of illness. Furthermore, the DIGS provides a structure for carefully defining both current and lifetime symptoms, as well as courseof-illness and comorbid states information. Questions on the age in which specific symptoms for diagnosis of psychiatric disorders appeared are part of the DIGS. DIGS requires the presence of 3 or more positive criteria for a given substance, to characterize substance dependence. ${ }^{14}$ 
For the diagnosis of depressive disorder the interview assesses both the most severe and the current depressive episodes. A current episode is defined as at least one week duration of feeling depressed, sad, blue, or irritable, or not enjoying usual activities within the past 30 days. If the current episode does not meet criteria, but the patient describes another episode meeting the criteria, the diagnosis for lifetime depression is made. All data from the full spectrum of potential depressive symptoms were entered into the OPCRIT (Operational Criteria Checklist for Psychotic IIIness) 3.4 database program. ${ }^{18,19}$

The OPCRIT system is used as a facilitator for a poly-diagnostic approach for psychiatric disorders. OPCRIT comprises a 90-item checklist of signs and symptoms (each item has a detailed definition or specification included in a glossary) and a suite of computer programs, which generate diagnoses according to the operational criteria of 12 major classificatory systems (e.g. DSM-III, DSM-III R, DSM-IV or ICD-10). In the present study, the diagnosis of depression was set to use DSM-IV criteria. ${ }^{18,19}$

In order to ensure a standardized use of the questionnaires, the investigators who were applying the questionnaires were trained and periodically monitored through written instructions and supervision. The reliability between interviewers was assessed through the Kappa coefficient and ranged from 1 to 0.96 .

\section{Statistical analysis}

The analysis was performed using the Statistical Package for the Social Sciences (SPSS 11.0). Quantitative data were described by mean and standard deviation, and qualitative data by absolute frequency and percentage. The categorical variables were compared through the chi-square test and odds ratios (OR) were calculated with the respective $95 \%$ confidence intervals $(\mathrm{Cl})$. As to identify associations between a given factor and drug dependence a $p<0.05$ was assumed.

Logistic regression analysis was applied to explore the association between illicit drug dependence and depression or other risk factors. Drug dependence was the dependent variable and factors such as sociodemographic, adverse experiences during childhood, alcohol use or dependence, and depression were the independent variables. Variables with $p<0.20$ in bivariate analysis were selected to be included in multivariate analysis. These variables were then introduced into the regression model using a stepwise forward procedure.

\section{Results}

Four hundred and eleven individuals ( 137 cases and 274 controls) were included in the study. The sociodemographic characteristics of the sample are summarized in Table 1. Age, ethnic background and residence district of the respondents were evenly distributed between cases and controls. Being male, single or divorced, living with parents, having low socioeconomic status and poor schooling were factors associated with the group of subjects dependent on illicit drugs. The two groups also differed in respect to occupational status, since most of the individuals in the control group worked or were students at the time of the study and the individuals in the

Table 1 - Distribution of drug dependent and non-dependent drug subjects according to sociodemographic variables

\begin{tabular}{|c|c|c|c|c|}
\hline Variable & $\begin{array}{c}\text { Drug dependent } \\
\qquad(\%)\end{array}$ & $\begin{array}{c}\text { Non-dependent } \\
\mathrm{N}(\%)\end{array}$ & $\mathrm{p}$ & $\begin{array}{l}\text { Odds Ratio } \\
(95 \% \mathrm{Cl})\end{array}$ \\
\hline \multicolumn{5}{|l|}{ Sex } \\
\hline Female* & $20(14.6)$ & $205(74.8)$ & & 1.0 \\
\hline Male & $117(85.4)$ & $69(25.2)$ & $<0.001$ & $17.4(9.8-31.3)$ \\
\hline \multicolumn{5}{|l|}{ Age (years) } \\
\hline $28-40^{*}$ & $56(41)$ & $115(42)$ & & 1.0 \\
\hline $16-27$ & $81(59)$ & $159(58)$ & 0.459 & $1.04(0.7-1.7)$ \\
\hline \multicolumn{5}{|l|}{ Race } \\
\hline Non-white (black/mulatto) ${ }^{*}$ & $26(19)$ & $59(21.5)$ & & 1.0 \\
\hline White & $111(81)$ & $21578.5)$ & 0.636 & $1.2(0.7-2.0)$ \\
\hline \multicolumn{5}{|l|}{ Marital status } \\
\hline Married/living w partner* & $46(33.6)$ & $154(56.2)$ & & 1.0 \\
\hline Single/separated/divorced & $91(66.4)$ & $120(43.8)$ & $<0.001$ & $2.5(1.6-3.9)$ \\
\hline \multicolumn{5}{|l|}{ Schooling (years) } \\
\hline high school and college* & $32(23.4)$ & $106(38.7)$ & & 1.0 \\
\hline 6th to 8 th grade elementary school** & $54(39.4)$ & $103(37.6)$ & & $1.7(1.0-3.0)$ \\
\hline $\begin{array}{l}\text { no schooling or up to } 5 \text { th grade } \\
\text { elementary school }\end{array}$ & $51(37.2)$ & $65(23.7)$ & 0.002 & $2.6(1.5-4.6)$ \\
\hline \multicolumn{5}{|l|}{ Labor activity } \\
\hline Work and/or study* & $77(56.2)$ & $196(71.5)$ & & 1.0 \\
\hline Does not work or study/unemployed & $60(43.8)$ & $78(28.5)$ & 0.003 & $2.0(1.5-1.2)$ \\
\hline \multicolumn{5}{|l|}{ Place of residence } \\
\hline Countryside* & $6(4.4)$ & $11(4)$ & & 1.0 \\
\hline Metropolitan area & $38(27.7)$ & $84(30.7)$ & & $0.8(0.3-2.8)$ \\
\hline Porto Alegre & $93(67.9)$ & $179(65.3)$ & 0.826 & $0.9(0.3-3.0)$ \\
\hline \multicolumn{5}{|l|}{ With whom lives } \\
\hline Spouse/children* & $41(29.9)$ & $163(59.5)$ & & 1.0 \\
\hline Relatives/other & $27(19.7)$ & $35(12.8)$ & & $3.1(1.6-5.9)$ \\
\hline Parents (parents/mother/father) & $49(35.8)$ & $62(22.6)$ & & $3.1(1.8-5.4)$ \\
\hline Alone & $20(14.6)$ & $14(5.1)$ & $<0.001$ & $5.7(2.5-13.1)$ \\
\hline \multicolumn{5}{|l|}{ Family income } \\
\hline$>2 \mathrm{MW}^{*}$ & $45(34.1)$ & $143(54.6)$ & & 1.0 \\
\hline$\leq 2 \mathrm{MW}^{* * *}$ & $87(65.9)$ & $119(45.4)$ & $<0.001$ & $2.3(1.5-3.6)$ \\
\hline
\end{tabular}

* Category of variable that serves as reference for the calculation of the odds ratios

** Included in this category are supplementary high school courses and technical courses

$* * *$ Minimum wage $(M W)$ in effect at the time of the study $=R \$ 180.00$ 
drug-dependent group were often not engaged in any study or labor activities ( $p=0.003$; OR $=2.0 ; 95 \% \mathrm{Cl}, 1.5-1.2$ ). The mean family income was $2.5 \pm 2.4$ minimum wages for the cases and $3.5 \pm 2.7$ minimum wages for the controls $(p<0.001 ; \mathrm{OR}=2.3$; 95\% Cl, 1.5-3.6).

The distribution of variables in respect to adverse experiences during childhood and adolescence, the use of drugs by friends and relatives, and spiritual support, and their corresponding odds ratios in respect to illicit drug dependence, for both cases and controls are summarized in Table 2. Verbal or sexual abuse during childhood and adolescence, religion, and spiritual support were not associated with dependence on illicit drugs. The adverse experiences during childhood that were different between the two groups were: the experienced physical abuse $(p=0.007 ; \mathrm{OR}=1.8 ; 95 \% \mathrm{Cl}$, $1.2-2.8)$, history of battered mother $(p<0.001$; OR $=2.7 ; 95 \%$ $\mathrm{Cl}, 1.7-4.4)$, or parental separation $(\mathrm{p}=0.027$; OR $=1.6 ; 95 \%$ $\mathrm{Cl}, 1.2-2.5)$, more prevalent among the dependents. Having contact with drug users, through family $(\mathrm{p}<0.001 ; \mathrm{OR}=12 ; 95 \% \mathrm{Cl}$, 4.2-36.8) or friends ( $<<0.001$; OR $=169.4$; $95 \% \mathrm{Cl}, 25.2-$ 3310.7) was also more prevalent among the drug dependents.

The data indicate that the percentage of individuals who have used alcohol at least once in life (lifetime alcohol) is greater in cases (92\%) than in controls (43.1\%) $(p<0.001$; OR $=15.1$; $95 \% \mathrm{Cl}, 7.5-31$ ). On the other hand, an association was found between alcohol dependence (according to the AUDIT) and illicit drug dependence ( $p<0.001$; OR $=16.1$; 95\% Cl, 9.2-28.4). As with illicit drug dependence, an unequal distribution between genders was noticed for alcohol dependence. Alcohol dependence was found to be more prevalent among males ( $p<0.001$; $\mathrm{OR}=8.1 ; 95 \% \mathrm{Cl}$, 4.6-14).

Dependence prevalence in the cases was $80.3 \%$ for cannabis, $82.5 \%$ for cocaine and $27 \%$ for inhalants. By definition we did not have any dependent individual in the control group. Among individuals with drug dependence, $31 \%$ were addicted to only one substance, $49 \%$ to 2 substances, and $20 \%$ were dependent on cannabis, cocaine and inhalants. The mean duration of drug use was 11 years for cannabis dependents, 8 years for cocaine, and 7 years for inhalants. Most of the cases had used cannabis $(82.4 \%)$ or cocaine $(80 \%)$ in the last 30 days; the use of inhalants in the last month was described by $43 \%$ of the cases. The median time lag since the last use was 3 days for cannabis, 4 days for cocaine, and 30 days for inhalants.

The results of the logistic regression analysis are presented in Table 3. Being male was found to be a risk factor, increasing the chances of drug dependence $(p<0.001 ;$ OR $=36.8 ; 95 \% \mathrm{Cl}$, 11.8-114). Notably, the large variation in confidence level was mainly due to the small number of female individuals. Within the sociodemographic variables only occupational status remained associated with drug dependence. "Not working or studying" and "unemployed" increased five fold the chance of dependence on illicit drugs ( $p=0.002 ;$ OR $=5.0 ; 95 \% \mathrm{Cl}, 1.8-13$ ). No significant associations remained detected between dependence on illicit drugs and marital status, schooling, with who lives and family income.

After the multivariate model, physical abuse, battered mother and parental separation or divorce were also not significantly associated. Having parents $(p=0.006 ; \mathrm{OR}=18.9 ; 95 \% \mathrm{Cl}$,

Table 2 - Distribution of drug dependent and non-dependent drug subjects according to variables related to adverse experiences during childhood

\begin{tabular}{|c|c|c|c|c|}
\hline Variable & $\begin{array}{c}\text { Drug dependent } \\
\qquad N(\%)\end{array}$ & $\begin{array}{c}\text { Non-dependent } \\
N(\%)\end{array}$ & $\mathbf{p}$ & $\begin{array}{l}\text { Odds Ratio } \\
(95 \% \mathrm{Cl})\end{array}$ \\
\hline \multicolumn{5}{|l|}{ Verbal abuse } \\
\hline $\mathrm{No}^{*}$ & $104(77)$ & $224(82.1)$ & & 1.0 \\
\hline Yes & $31(23)$ & $49(17.9)$ & 0.286 & $1.4(0.8-2.3)$ \\
\hline \multicolumn{5}{|l|}{ Physical abuse } \\
\hline $\mathrm{No}^{*}$ & $65(47.4)$ & $170(62)$ & & 1.0 \\
\hline Yes & $72(52.6)$ & $104(38)$ & 0.007 & $1.8(1.2-2.8)$ \\
\hline \multicolumn{5}{|l|}{ Battered mother } \\
\hline No* & $76(58.9)$ & $217(79.5)$ & & 1.0 \\
\hline Yes & $53(41.1)$ & $56(20.5)$ & $<0.001$ & $2.7(1.7-4.4)$ \\
\hline \multicolumn{5}{|l|}{ Sexual abuse } \\
\hline No* & $120(87.6)$ & $239(87.2)$ & & 1.0 \\
\hline Yes & $17(12.4)$ & $35(12.8)$ & 1.000 & $1.0(0.5-1.9)$ \\
\hline \multicolumn{5}{|c|}{ Parental separation or divorce } \\
\hline $\mathrm{No}^{*}$ & $63(46)$ & $159(58)$ & & 1.0 \\
\hline Yes & $74(54)$ & $115(42)$ & 0.027 & $1.6(1.1-2.5)$ \\
\hline \multicolumn{5}{|l|}{ Parents users } \\
\hline $\mathrm{No}^{*}$ & $112(81.8)$ & $269(98.2)$ & & 1.0 \\
\hline Yes & $25(18.2)$ & $5(1.8)$ & $<0.001$ & $12.0(4.2-36.8)$ \\
\hline \multicolumn{5}{|l|}{ Siblings users } \\
\hline $\mathrm{No}^{*}$ & $89(66.4)$ & $230(83.9)$ & & 1.0 \\
\hline Yes & $45(33.6)$ & $44(16.1)$ & $<0.001$ & $2.6(1.6-4.4)$ \\
\hline \multicolumn{5}{|l|}{ Friends users } \\
\hline No* & $1(0.7)$ & $152(55.5)$ & & 1.0 \\
\hline Yes & $136(99.3)$ & $122(44.5)$ & $<0.001$ & $169.4(25.2-3310.7)$ \\
\hline \multicolumn{5}{|l|}{ Spiritual support } \\
\hline Yes* & $97(71.3)$ & $202(73.7)$ & & 1.0 \\
\hline No & $39(28.7)$ & $72(26.3)$ & 0.692 & $1.1(0.7-1.8)$ \\
\hline \multicolumn{5}{|l|}{ Religion } \\
\hline Yes* & $104(75.9)$ & $207(75.5)$ & & 1.0 \\
\hline No & $33(24.1)$ & $67(24.5)$ & 1.000 & $1.0(0.6-1.6)$ \\
\hline
\end{tabular}

* Category of variable that serves as reference for the calculation of the odds ratios 
Table 3 - Risk factors for dependence on illicit drugs: a logistic regression model

\begin{tabular}{|c|c|c|}
\hline Variables* & Variables & $\begin{array}{l}\text { Adjusted OR } \\
(95 \% \mathrm{Cl})\end{array}$ \\
\hline Sex & $\begin{array}{l}\text { Female } \\
\text { Male } \\
\text { p value }\end{array}$ & $\begin{array}{c}1.0 \\
36.8(11.8-114) \\
<0.001\end{array}$ \\
\hline Marital status & $\begin{array}{l}\text { Married/living w partner } \\
\text { Single/separated/divorced } \\
\mathrm{p} \text { value }\end{array}$ & $\begin{array}{c}1.0 \\
1.4(0.6-3.5) \\
0.43\end{array}$ \\
\hline Schooling & $\begin{array}{l}\text { High school and college/6th to } \\
\text { 8th grade elementary school } \\
\text { No schooling or up to } 5 \text { th grade } \\
\text { elementary school } \\
\text { p value }\end{array}$ & $\begin{array}{c}1.0 \\
1.6(0.8-2.9) \\
0.13\end{array}$ \\
\hline Labor activity & $\begin{array}{l}\text { Work and/or study } \\
\text { Do not work or } \\
\text { study/unemployed } \\
\text { p value }\end{array}$ & $\begin{array}{c}1.0 \\
5.0(1.8-13) \\
0.002\end{array}$ \\
\hline With whom lives & $\begin{array}{l}\text { Spouse/children/ } \\
\text { relatives/parents/other } \\
\text { Alone } \\
\text { p value }\end{array}$ & $\begin{array}{c}1.0 \\
2.5(0.4-16.1) \\
0.33\end{array}$ \\
\hline Family income & $\begin{array}{l}>2 \mathrm{MW} \\
\leqslant 2 \mathrm{MW} \\
\mathrm{p} \text { value }\end{array}$ & $\begin{array}{c}1.0 \\
1.9(0.8-4.7) \\
0.15\end{array}$ \\
\hline Physical abuse & $\begin{array}{l}\text { No } \\
\text { Yes } \\
\text { p value }\end{array}$ & $\begin{array}{c}1.0 \\
0.6(0.3-1.6) \\
0.3\end{array}$ \\
\hline Battered mother & $\begin{array}{l}\text { No } \\
\text { Yes } \\
\text { p value }\end{array}$ & $\begin{array}{c}1.0 \\
0.9(0.4-2.6) \\
0.9\end{array}$ \\
\hline $\begin{array}{l}\text { Parental } \\
\text { separation or } \\
\text { divorce }\end{array}$ & $\begin{array}{l}\text { Yes } \\
p \text { value }\end{array}$ & $\begin{array}{c}0.9(0.4-2.4) \\
0.9\end{array}$ \\
\hline Parents users & $\begin{array}{l}\text { No } \\
\text { Yes } \\
\text { p value }\end{array}$ & $\begin{array}{c}1.0 \\
18.9(2.3-158) \\
0.006\end{array}$ \\
\hline Siblings users & $\begin{array}{l}\text { No } \\
\text { Yes } \\
\text { p value }\end{array}$ & $\begin{array}{c}1.0 \\
1.6(0.6-4.4) \\
0.36\end{array}$ \\
\hline Friends users & $\begin{array}{l}\text { No } \\
\text { Yes } \\
\text { p value }\end{array}$ & $\begin{array}{c}1.0 \\
64.4(6.5-636.8) \\
<0.001\end{array}$ \\
\hline Alcohol use & $\begin{array}{l}\text { Never used } \\
\text { Lifetime use } \\
p \text { value }\end{array}$ & $\begin{array}{c}1.0 \\
5.12(1.6-15.9) \\
0.005\end{array}$ \\
\hline $\begin{array}{l}\text { Dependence on } \\
\text { alcohol }\end{array}$ & $\begin{array}{l}\text { Non-dependent }(\text { AUDIT }<8 \text { ) } \\
\text { Dependent }(\text { AUDIT } \geq 8) \\
\text { p value }\end{array}$ & $\begin{array}{c}1.0 \\
3.4(1.3-8.7) \\
0.01\end{array}$ \\
\hline Depression & $\begin{array}{l}\text { No } \\
\text { Yes } \\
\text { p value }\end{array}$ & $\begin{array}{c}1.0 \\
4.9(1.9-12.7) \\
0.001\end{array}$ \\
\hline
\end{tabular}

* Controlling for sex, marital status, schooling, labor activity, with whom lives, family income, physical abuse, battered mother, parental separation or divorce, parents users, sibling users, friends users, alcohol use, alcohol dependence and depression.

2.3-158) or friends ( $p<0.001 ; \mathrm{OR}=64.4 ; 95 \% \mathrm{Cl}, 6.5-636$ ) who were drug users showed an important association with drug dependence. Among the alcohol-related variables, both alcohol use and dependence remained associated with dependence on illicit drugs. The comparison of the odds ratios found before adjustment $(p<0.001 ; O R=15.1 ; 95 \% \mathrm{Cl}, 7.5-31 ; p<0.001 ; O R=16.1$; $95 \% \mathrm{Cl}$ 9.2-28.4) with the ones after adjustment ( $p=0.005$; $\mathrm{OR}=5.1 ; 95 \% \mathrm{Cl}, 1.6-15.9 ; \mathrm{p}=0.01 ; \mathrm{OR}=3.4 ; 95 \% \mathrm{Cl}$,
1.3-8.7) shows an important decrease in risk for this association, pointing to important interactions of the variables with alcohol use and dependence, respectively, probably because there are similar mechanisms for alcohol and illicit drug dependence. Depression remained significantly related to illicit drug dependence after adjustment ( $p=0.001 ; \mathrm{OR}=4.9 ; 95 \% \mathrm{Cl}, 1.9-12.7$ ). As the adjusted odds ratio of depression is comparable to the one observed in the unadjusted odds ( $p<0.001$; OR $=4.2 ; 95 \% \mathrm{Cl}, 2.7-6.7$ ), this factor is seen to have an effect that is independent of the other factors on drug dependence.

A total of 80 individuals dependent on illicit drugs (58.4\%) were depressed, according to DSM-IV criteria. In the control group, depression was less frequent, affecting $24.8 \%$ of the individuals ( $p<0.001 ; \mathrm{OR}=4.2,95 \% \mathrm{Cl}, 2.7-6.7)$. In the individuals who had both drug dependence and depression, we investigated which disorder started earlier. Ninety-one percent of the individuals with drug dependence reported abusing drugs as the preceding disorder, $6.4 \%$ reported mood changes before drug abuse, and $2.6 \%$ reported that both phenomena happened at the same time. Accordingly, the mean age of the first experience with illicit drugs was $14.6 \pm 2.9$ years for cannabis, $15.5 \pm 4.6$ years for inhalants, and $18.8 \pm$ 5.3 years for cocaine while the onset of depression occurred at the mean age of $22.4 \pm 1.1$ years.

\section{Discussion}

This study confirms that dependence on illicit drugs is associated with multiple biological, social, psychological, and familial characteristics. Many of the sociodemographic characteristics of our sample of individuals with drug dependence did not differ from those described in other studies. ${ }^{20}$ Although the low socioeconomic condition and school withdrawal have been described in the literature as risk factors for drug abuse, ${ }^{21,22}$ we could not replicate the finding probably because our study population was composed by low-income individuals in both cases and controls. Furthermore, non drug users in this population usually drop out of school to work and help with their family income, while most users or drug dependents did not have a steady job and use free time to use drugs. ${ }^{23}$ On the other hand, individuals who did not work or study and were unemployed showed a significant association with dependence. These characteristics may be related to low motivation for work or study among the drug dependents. ${ }^{23}$

Many variables that reflect adverse experiences during childhood, such as physical, emotional or sexual abuse, neglect, drug abuse by parents, relatives, siblings or friends who use drugs, divorce and other family dysfunctions have been identified as factors related to the use and abuse of drugs. ${ }^{24,25}$ Negative consequences from such behaviors might raise negative emotions that escalate into depression. ${ }^{6}$ In our study, after the variables were included in the final regression model, only having parents and friends who abuse drugs remained associated with drug dependence. Having contact with drug users during adolescence is commonly reported as a risk factor by other studies. ${ }^{26,27}$ Parents who have problems with drugs and alcohol may model drug use, enhance opportunities for drug or alcohol use by having substances available, or fail to monitor adolescents' behavior, thus increasing opportunity for drug and alcohol use, abuse, and dependence. ${ }^{27-29}$ Children of substancedependent parents are at a high risk for subsequent substance abuse also because they grow up in dysfunctional families that negatively affect their capacity for normal development. ${ }^{30}$ In accordance with the findings of Dishion \& Owen (2002), drug dependence in our sample was associated with friends who use drugs. The friends can 
influence drug use and, conversely, drug use impacts the selection of friends; sharing drugs connects individuals within peer groups. ${ }^{26}$

The lack of significance of the other variables could be ascribed to colinearity between them; thus different variables may represent the same event. Early childhood trauma can lead to an array of negative health outcomes and behaviors, including substance abuse. ${ }^{31}$ Among women, sexual abuse has been reported to be a risk factor for the development of drug use disorders; ${ }^{32,33}$ however, this relationship has not been thoroughly investigated in men. ${ }^{32,34}$ Our results do not indicate that physical and sexual abuse during childhood was associated with drug dependence. These findings are based on a population composed predominately by males. The gender difference may result in part from differences in how men and women respond to childhood victimization. Men may become aggressive and women may be more prone to internalizing pain and suffering, which then may lead to self-destructive behaviors, including drug abuse. ${ }^{35}$ This hypothesis remains to be tested in this population. However, our results are congruent with other studies, which did not find significant relationships between parental alcohol use and the various types of child abuse ${ }^{36}$ and are in accordance with other findings in the sense that childhood abuse is not a causal factor in the development of substance abuse. ${ }^{37}$

The causal relationship between depression and substance use disorder is complex and was recently reviewed. The explanations for the co-occurrence of these disorders may include: drug dependence may create an increased vulnerability or risk for depression; depression may result from the associated social, interpersonal, and occupational problems that result from dependence; depression may result from the biologic effects of drug dependence. ${ }^{37}$

Besides confirming the comorbidity between drug dependence and depression ${ }^{2,3}$ our findings also provide evidence illicit drug dependence being the primary disorder, whenever depression is also present. ${ }^{6}$ It has been described that the presence of drug abuse increased the risk for depression by a factor of 4.7 and the lifetime prevalence of drug abuse in mood disorders is $19.4 \% .{ }^{1}$ Our results show a very similar OR (4.9) of depression in drug dependent individuals. It also shows a significant overlap between environmental variables that are associated with substance abuse and depression that could contribute to this comorbidity, as seen in other studies. ${ }^{38}$

Our results point to the much higher probability in the population that drug abuse is followed by depression than the probability of depression being followed by drug abuse. However, one may not rule out that differences might occur in risk factors and in the neurobiology of comorbidity. ${ }^{3}$ It also does not rule out that both drug dependence and depression may have started concomitantly, but presented different temporal courses between its beginnings and current diagnosis. In general, drug abuse is diagnosed first, due to its more evident nature. In our study, individuals with drug dependence recalled being very young teenagers in the beginning of their drug use, claiming drug use onset before depression. This may be suggested considering the reports given by the drug dependent patients that they perceived being depressed only when young adults. However, no one can actually state that they were under-diagnosed for depressed mood before that time. These results also agree with other observations against the self-treatment hypothesis and describe that drug abuse may play a casual or modulating role in developing depression among adolescents. ${ }^{6,11}$ However, more studies are necessary to elucidate this issue by establishing the risk of progressing from drug use to drug dependence in young individuals who are diagnosed with depressive disorders when in childhood or pre-teen years.

Rev Bras Psiquiatr. 2009;31(2):106-13
One of the limitations of this study reflects the general difficulty inherent in case-control studies: recall bias. That is, individuals whose drug abuse or dependence has persisted for several years may have more difficulty in recalling previous manifestations of both psychiatric disorders and other exposures (obtained through questionnaires). This may lead to misinformation about their past experiences. All measurements were based on self-report data and the accuracy of the reports depends on the willingness of respondents to disclose illicit drug dependence information. It is possible that this limitation may have led to some under-reporting of drug dependence. Additionally, depression is likely to be under-diagnosed and early depression symptoms are likely to be unrecognized. Thus, the results of this study should be interpreted with caution as giving lower limit estimates of actual incidence of illicit drugs dependence or depression. Moreover, our study is characterized by a sample predominantly with a lower income and socioeconomic status, limiting the generalization of our findings to other social classes.

Finally, depression and other psychiatric comorbidities are clinically significant disorders among drug users in this Latin American population as seen in North-hemisphere countries. 1,5,39 The high prevalence of lifetime depression in our sample is consistent with other findings. 5,40 The comorbidity between depression and substance abuse disorders may be related to common risk factors. As the age of drug use far preceded the age of depression, it may be stated that in this sample, depression is not likely a cause for substance abuse disorders. Therefore, our data suggest that, for most patients, drug use precedes depressive pathologies, which may then result from regular drug use, ${ }^{40,41}$ the life-changing consequences of drug abuse, ${ }^{41,42}$ or the challenges of abstinence. ${ }^{43,44}$ This possibility also explains the discrepancy of having more females depressed and more males abusing drugs. ${ }^{11}$

\section{Acknowledgments}

All authors of the manuscript declare that there were no conflicts of interest that could have influenced the results of the research. This study was approved by the committee of ethics (03/2001) before its accomplishment. HMTB is Conselho Nacional d Desenvolvimento Científico e Tecnológico (CNPq) researcher $1 \mathrm{C}$. 


\section{Disclosures}

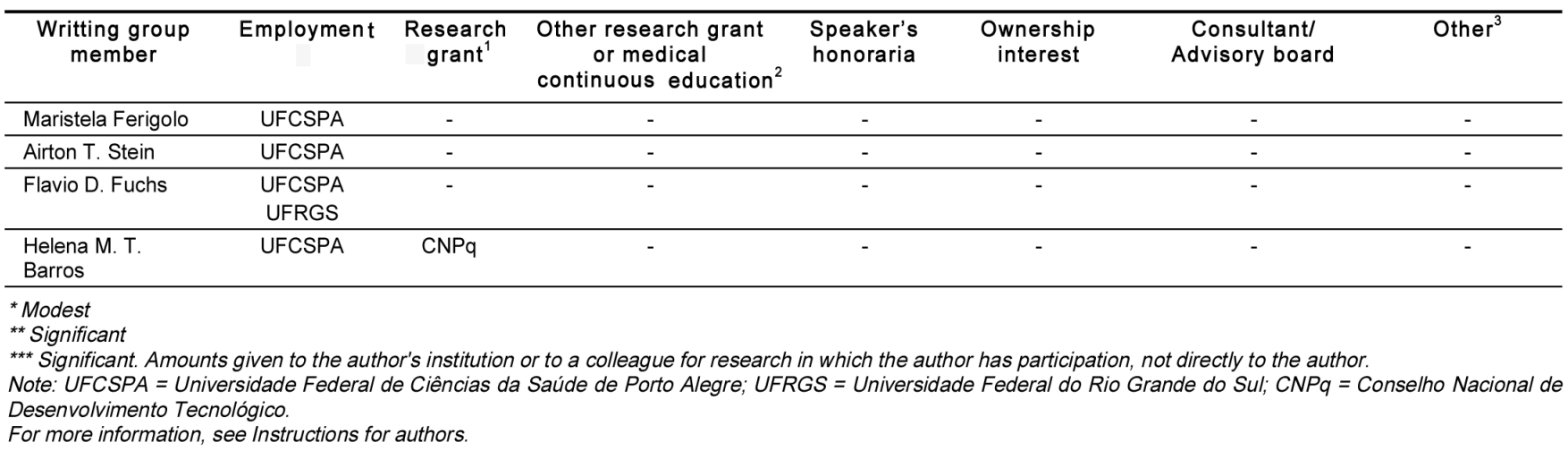

\section{References}

1. Regier DA, Farmer ME, Rae SD, Locke BZ, Keith SJ, Judd LL, Goodwin FK. Comorbidity of mental disorders with alcohol and other drug abuse. Results from the Epidemiologic Catchment Area (ECA) Study. JAMA. 1990;264(19):2511-8.

2. Davis L, Uezato A, Newell JM, Fazier E. Major depression and comorbid substance use disorders. Curr Opin Psychiatry. 2008;21(1):14-8.

3. Volkow $\mathrm{N}$. The reality of comorbidity: depression and drug abuse. Biol Psychiatry. 2004;56(10):714-7.

4. Swendsen JD, Merikangas KR. The comorbidity of depression and substance use disorders. Clin Psychol Rev. 2000;20(2):173-89.

5. Deykin EY, Buka SL, Zeena TH. Depressive illness among chemically dependent adolescents. Am J Psychiatry. 1992;149(10):1341-7.

6. Libby AM, Orton HD, Stover SK, Riggs PD. What came first, major depression or substance use disorder? Clinical characteristics and substance use comparing teens in a treatment cohort. Addict Behav. 2005;30(9):1649-62.

7. Ramsey SE, Kahler CW, Read JP, Stuart GL, Brown RA. Discriminating between substance-induced and independent depressive episodes in alcohol dependent patients. J Stud Alcohol. 2004;65(5):672-6.

8. Rey JM, Sawyer MG, Raphael B, Patton GC, Lynskey M. Mental health of teenagers who use cannabis. Results of an Australian survey. $\mathrm{Br}$ J Psychiatry. 2002;180(3):216-21.

9. Silberg J, Rutter M, D'Onofrio B, Eaves L. Genetic and environmental risk factors in adolescent substance abuse. J Child Psychol Psychiatry. 2003;44(5):664-76.

10. Brook DW, Brook JS, Zhang C, Cohen P, Whiteman M. Drug use and the risk of major depressive disorder, alcohol dependence, and substance use disorders. Arch Gen Psychiatry. 2002;59(11):1039-44.

11. Hallfors DD, Waller MW, Bauer D, Ford CA, Halpern CT. Which comes first in adolescence sex and drugs or depression? Am J Prev Med. 2005;29(3):163-70.

12. Brook DW, Brook JS, Richter L, Whiteman M, Arencibia-Mireles O, Masci JR. Marijuana use among the adolescent children of high-risk drug-abusing fathers. Am J Addict. 2002;11(2):95-110.

13. Azevedo MH, Valente J, Macedo A, Dourado A, Coelho I, Pato M, Pato C. Versão portuguesa da entrevista diagnóstica para estudos genéticos. Psiquiatr Clin. 1993;14(4):213-7.

14. Nurnberger JI Jr, Blehar MC, Kaufmann CA, York-Cooler C, Simpson SG, Harkavy-Friedman J, Severe JB, Malaspina D, Reich T, collaborators from the NIMH Genetics Initiative. Diagnostic Interview for Genetic Studies: Rationale, Unique Features, and Training. Arch Gen Psychiatry. 1994;51(11):859-94.

15. Méndez EB. Uma versão brasileira do AUDIT (Alcohol Use Disorders Identification Test) [dissertação]. Universidade Federal de Pelotas: Rio Grande do Sul; 1999.

16. Galduróz JCF, Noto AR, Nappo AS, Carlini EA. Trends in drug use among students in Brazil: analysis of four surveys in 1987, 1989, 1993 and 1997. Braz J Med Biol Res. 2004;37(4):523-31.

17. Straus MA. Measuring intrafamily conflict and violence: The Conflict Tactics (CT) scales. In: Straus MA, Gelles RJ, editors. Physical violence in American families: risk factors and adaptations to violence in 8,145 families. New Brunswick, NJ: Transaction Publications; 1990. p.29-48.

18. Azevedo MH, Soares MJ, Coelho I, Dourado A, Valente J, Macedo A, Pato $\mathrm{M}$, Pato $\mathrm{C}$. Using consensus OPCRIT diagnoses. An efficient procedure for best-estimate lifetime diagnoses. Br J Psychiatry. 1999;175:154-7.

19. Williams J, Farmer AE, Ackenhell M, Kaufmann CA, McGuffin P, the OPCRIT reliability research group. A multicentre inter-rater reliability study using the OPCRIT computerized diagnostic system. Psychol Med. 1996;26(4):775-83.

20. Castel S, Malbergier A. Farmacodependências - Estudo comparativo de uma população atendida em serviço especializado: 1984-1988. Rev ABP APAL. 1989;11(3):126-32.

21. De Micheli D, Formigoni ML. Are reasons for the first use of drugs and family circumstances predictors of future use patterns? Addict Behav. 2002;27(1):87-100.

22. Kliewer W, Murrelle L. Risk and protective factors for adolescent substance use: findings from a study in selected central American countries. J Adolesc Health. 2007;40(5):448-55.

23. Sanchez ZM, De Oliveira GL, Nappo SA. Main reasons for non-use of illicit drugs by young population exposed to risk situations. Rev Saude Publica. 2005;39(4):599-605.

24. Dube SR, Felitti VJ, Dong M, Chapman DP, Giles WH, Anda RF. Childhood abuse, neglect, and household dysfunction and the risk of illicit drug use: the adverse childhood experiences study. Pediatrics. 2003;111(3):564-72.

25. Eitle $D$. The moderating effects of peer substance use on the family structure-adolescent substance use association: quantity versus quality of parenting. Addict Behav. 2005;30(5):963-80.

26. Dishion TJ, Owen LD. A longitudinal analysis of friendships and substance use: bidirectional influence from adolescence to adulthood. Dev Psychol. 2002;38(4):480-91.

27. Hoffmann JP, Cerbone FG. Parental substance use disorder and the risk of adolescent drug abuse: an event history analysis. Drug Alcohol Depend. 2002;66(3):255-64.

28. Cleveland MJ, Feinberg ME, Bontempo DE, Greenberg MT. The role of risk and protective factors in substance use across adolescence. J Adolesc Health. 2008;43(2):157-64.

29. Schinke S, Fang L, Cole KC. Substance use among early adolescent girls: risk and protective factors. J Adolesc Health. 2008;43(2):191-4.

30. Moss HB, Lynch KG, Hardie TL, Baron DA. Family functioning and peer affiliation in children of fathers with antisocial personality disorder and substance dependence: associations with problem behaviors. Am J Psychiatry. 2002;159(4):607-14.

31. Dube SR, Felitti VJ, Dong M, Chapman DP, Giles WH, and Anda RF. Childhood abuse, neglect, and household dysfunction and the risk of illicit drug use: the adverse childhood experiences study. Pediatrics. 2003;111(3):564-72.

32. Widom CS, Hiller-Sturmhöfel S. Alcohol abuse as a risk factor for and consequence of child abuse. Alcohol Res Health. 2001;25(1):52-7. 
33. Wilsnack SC, Vogeltanz ND, Klassen AD, Harris TR. Childhood sexual abuse and women's substance abuse: national survey findings. J Stud Alcohol. 1997;58(3):264-71.

34. Simpson TL, Miller WR. Concomitance between childhood sexual and physical abuse and substance use problems. A review. Clin Psychol Rev. 2002;22(1):27-77.

35. Widom CS, Hiller-Sturmhöfel S. Alcohol abuse as a risk factor for and consequence of child abuse. Alcohol Res Health. 2001;25(1):52-7.

36. Harter ST, Taylor TL. Parental alcoholism, child abuse, and adult adjustment. J Subst Abuse. 2000;11(1):31-4.

37. Davis LL, Rush JA, Wisniewski SR, Rice K, Cassano P, Jewell ME, Biggs MM, Shores-Wilson K, Balasubramani GK, Husain MM, Quitkin FM, McGrath PJ. Substance use disorder comorbidity in major depressive disorder: an exploratory analysis of the Sequenced Treatment Alternatives to Relieve Depression cohort. Compr Psychiatry. 2005;46(2):81-9.

38. Kendler KS, Liu XQ, Gardner CO, McCullough ME, Larson D, Prescott CA. Dimensions of religiosity and their relationship to lifetime psychiatric and substance use disorders. Am J Psychiatry. 2003;160(3):496-503.

39. Kandel DB, Huang FY, Davies M. Comorbidity between patterns of substance use dependence and psychiatric syndromes. Drug A/cohol Depend. 2001;64(2):233-41.

40. Bovasso GB 2001. Cannabis abuse as a risk factor for depressive symptoms. Am J Psychiatry. 2001;158(12):2033-7.

41. Lopes CS, Coutinho ESF. Transtornos mentais como fatores de risco para o desenvolvimento de abuso/dependência de cocaína: estudo caso-controle. Rev Saude Publica. 1999;33(5):477-86.

42. Reilly D, Didcott P, Swift W, Hall W. Long-term cannabis use: characteristics of users in an Australian rural area. Addiction. 1998;93(6):837-46.

43. Gavin FH, Kleber HD. Abstinence symptomatology and psychiatric diagnosis in cocaine abusers. Arch Gen Psychiatry. 1986;43(2): 107-13.

44. Weinberg NZ, Glantz MD. Child psychopathology risk factors for drug abuse: overview. J Clin Child Psychol. 1999;28(3):290-7. 